\title{
Plant derived substances with anti-cancer activity: from folklore to practice
}

\author{
Marcelo Fridlender, Yoram Kapulnik and Hinanit Koltai* \\ Institute of Plant Sciences, Agricultural Research Organization, Volcani Center, Bet Dagan, Israel
}

Plants have had an essential role in the folklore of ancient cultures. In addition to the use as food and spices, plants have also been utilized as medicines for over 5000 years. It is estimated that $70-95 \%$ of the population in developing countries continues to use traditional medicines even today. A new trend, that involved the isolation of plant active compounds begun during the early nineteenth century. This trend led to the discovery of different active compounds that are derived from plants. In the last decades, more and more new materials derived from plants have been authorized and subscribed as medicines, including those with anti-cancer activity. Cancer is among the leading causes of morbidity and mortality worldwide. The number of new cases is expected to rise by about $70 \%$ over the next two decades. Thus, there is a real need for new efficient anti-cancer drugs with reduced side effects, and plants are a promising source for such entities. Here we focus on some plant-derived substances exhibiting anticancer and chemoprevention activity, their mode of action and bioavailability. These include paclitaxel, curcumin, and cannabinoids. In addition, development and use of their synthetic analogs, and those of strigolactones, are discussed. Also discussed are commercial considerations and future prospects for development of plant derived substances with anti-cancer activity.

Keywords: plant, active compounds, anti-cancer agents, folklore, chemoprevention

\section{Introduction}

Plants have had an essential role in the folklore of ancient cultures. In addition to the use as food and spices, plants have also been utilized as medicines for over 5000 years. Two remaining living traditions, the traditional Chinese medicine (TCM) and Ayurveda, the traditional Indian medicine (TIM) have provided most of the current knowledge related to medicinal plants (Goldman, 2001; Patwardhan et al., 2005). In TCM and TIM folklore, herbal medicines were prepared as teas, tinctures, poultices, powders, and other types of formulations (Balick and Cox, 1996; Samuelsson, 2004). The expertise to select the right plants, methods of drug concoction and their specific use has been first transferred orally from one generation to the next until set down (Kinghorn, 2001; Samuelsson, 2004).

It is estimated that $70-95 \%$ of the population in developing countries continues to use traditional medicines (Robinson and Zhang, 2011). Today medicinal herbs are defined as plants that contain valuable substances with therapeutic or beneficial effect in healing and prevention of various ailments in man and animals. Herbal products such as plant extracts, dry powders and parts of plants, fungi, and algae have been used as complementary treatments alongside conventional drugs (Li, 2002; Robinson and Zhang, 2011). 
A new trend, that involved the isolation of plant active compounds begun during the early nineteenth century. This tendency led to the discovery of the analgesic (painkilling) drugs morphine and codeine from opium (Papaver somniferum L.); cocaine from Erythroxylum coca; the cardiac glycoside, digitoxin that was isolated from Digitalis purpurea and Digitalis lanata that has been used for cardiac conditions and as an anti-cancer drug, and quinine from Cinchona calisaya Wedd. and Cinchona succirubra Pav. ex Klotzsch that has antipyretic (fever reducing), antimalarial, analgesic, and anti-inflammatory properties. Some of these molecules are still in use (Newman et al., 2000; Kinghorn, 2001; Butler, 2004; Samuelsson, 2004; Balunas and Kinghorn, 2005; Elbaz et al., 2012; Menger et al., 2013). Such natural compounds provide a huge variety, often with strong biological activity and therefore play a significant role in the development of therapeutics treatments (Butler, 2004; Balunas and Kinghorn, 2005; Gordaliza, 2007).

Discovery of plant-derived substances has evolved during the last 200 years due to the variety of experience and expertise needed in order to identify such compound. Initially, a plant is identified by a botanist or ethnobotanist, ethnopharmacologist, or plant ecologist. Next, plant extracts followed by biological screening assays are performed by a phytochemist to identify the potential therapeutic activity followed by isolation of the active compound. Finally, molecular biology studies are required to reveal the mode of action and relevant molecular targets. The combination of these fields determines an interdisciplinary approach termed pharmacognosy (Kinghorn, 2001; Balunas and Kinghorn, 2005).

Today, it is estimated that about $25-28 \%$ of all modern medicines are directly or indirectly derived from higher plants demonstrating the enormous medicinal potential of plants that has been known for thousands of years in traditional medicine (Samuelsson, 2004; Chin et al., 2006). In the last decades, more and more new materials derived from plants have been authorized and subscribed as medicines (Balunas and Kinghorn, 2005; Chin et al., 2006). Several important examples for plant origin medicines are Arteether (Artemotil'), a sesquiterpene lactone isolated from Artemisia annua and serves for treatment of malaria (Van Agtmael et al., 1999; Graul, 2004), Galantamine (Reminyl ${ }^{\circ}$ ) an amaryllidaceae alkaloid from Galanthus woronowii used for Alzheimer treatment due to its activity as a selective acetylcholinesterase inhibitor (Heinrich and Teoh, 2004; Pirttilä et al., 2004), Apomorphine hydrochloride (Apokyn ) a dopamine receptor agonist produced in Papaver somniferum L. used to treat Parkinson's disease (Deleu et al., 2004), Tiotropium bromide (Spiriva ) isolated from Atropa belladonna and used for to treat COPD (chronic obstructive pulmonary disease; Mundy and Kirkpatrick, 2004; Koumis and Samuel, 2005), Nitisinone (Orfadin ${ }^{\circ}$ ) a modified mesotrione from Callistemon citrinus that inhibits the 4-hydroxyphenylpyruvate dioxygenase (HPPD) enzyme and prevents accumulation of fumaryl and maleyl acetoacetate in the liver and kidneys (Hall et al., 2001; Mitchell et al., 2001).

Interestingly, many isolated substances against cancer are connected with interactions between plants and microbes. Such interactions are related to rhizospheric or endophytic bacteria, yeasts, and fungi. These microorganisms penetrate and reside within plants without injuring them or causing any disease. Furthermore, such microbes serve as a barrier for colonization by pathogenic microorganisms and participate in plant growth and plant defense response by production of a large variety of secondary metabolites (reviewed in Strobel and Daisy, 2003; Strobel et al., 2004; Ryan et al., 2008; Chandra, 2012; Kaul et al., 2012). Since almost all plants co-exist with at least one endophyte and many molecules have been isolated from such systems, this review does not aim to summarize this field and it should review somewhere else. Nonetheless, two recent studies revealed that extracts from Chaetomium globosum (Wang et al., 2012; Awad et al., 2014) and 5-Methyl phenazine-1-carboxylic acid that is produced by Pseudomonas putida (Kennedy et al., 2015) had cytotoxic effects against cancer cell lines. The similarity of secondary metabolites produce by endophytes and their hosts implies on gene transfer between them throughout co-evolution (Chandra, 2012). Taking advantage of biotechnology new drugs from endophytes can be manufactured in faster and controlled processes (Chandra, 2012; Kaul et al., 2012).

In addition to the drugs mentioned above, other plant-derived substances with anti-cancer activity such as Paclitaxel (Taxol ${ }^{\circ}$ ) and Camptothecin have been isolated and approved for use. Here we will focus on some plant-derived substances exhibiting anti-cancer activity, their mode of action and bioavailability. In addition, comparison of the use of natural vs. synthetic analogs as well as commercial consideration will be discussed.

\section{Examples for Plant-Derived Substances with Anti-Cancer Activity}

Cancer is among the leading causes of morbidity and mortality worldwide. In 2012, 8.2 million cancer related deaths and approximately 14 million new cases were counted. The number of new cases is expected to rise by about $70 \%$ over the next two decades. Among men, the five most common sites of cancer diagnosed in 2012 were lung, prostate, colorectum, stomach, and liver cancer. Among women the five most common sites diagnosed were breast, colorectum, lung, cervix, and stomach cancer. It is expected that annual cancer cases will rise from 14 million in 2012 to 22 within the next two decades (http://www.who. $\mathrm{int} /$ mediacentre/factsheets/fs297/en/ and references within).

Today, solid tumors are surgically removed and patients receive adjuvant radiation treatment and chemotherapy that cause severe sides effects and dramatically reduce quality of life. In addition, the toxicity of some treatments restricts their use and effectiveness. Certain types of cancer such as breast cancer, can be treated using biological drugs (Herceptin), however the cost of these drugs is very high and their effectiveness is limited in most cases to certain kinds of tumors. In many cases, the tumor develops resistance to a particular drug and the patient is transferred to a different drug. In addition, many patients are treated with a combination of several drugs. More on cancer treatment and survivorship statistics may be found in DeSantis et al. (2014) and references within. Thus, there is no doubt that there is a real need for new efficient anticancer drugs with reduced side effects, and plants are a promising source for such entities. Due to the importance of fighting cancer 
and the variety of potential molecules offered by plants, over $60 \%$ of anti-cancer drugs are directly or indirectly derived from this kingdom (Gordaliza, 2007).

Probably the most well-known plant-derived anti-cancer drug is Paclitaxel $\left(\mathrm{Taxol}^{\circ}\right)$. The cytotoxic activity of this taxane dipertene found in extracts from the bark of Taxus brevifolia Nutt. (Western yew) was first reported by Wani et al. (1971). Later on, other Taxus species were found to produce this molecule. Interestingly, In 1993, Taxol was also found to be produced at low levels by Taxus' endophytic fungus Taxomyces andreanae (Stierle et al., 1993) and later on by other endophytic fungi (Guo et al., 2006) allowing its possible production by future microorganism fermentation. Taxol's molecular structure is based on the A, B, and $\mathrm{C}$ rings that harbor two hydroxyl groups, two acetyl groups, one benzoyl group and an oxetane ring. The side chain A ring together with the benzoyl group at $\mathrm{C} 2$ and the oxetane ring are responsible for Taxol's anti-cancer activity. The C3 amide-acyl group in the C12 chain maintains this activity and the hydroxyl group at C2 enhances it (Kingston, 2000, 2001; Malik et al., 2011).

As other plant-derived compound such as vinca alkaloids, Taxol disrupts microtubule function. However, in contrast to vinca alkaloids that disrupt microtubule assembly by binding depolymerized microtubules, Taxol (essentially all taxanes) inhibits microtubule disassembly by binding the polymerized microtubules (Xiao et al., 2006; Hait et al., 2007; Prota et al., 2013). Microtubules are composed of $\alpha \beta$-tubulin heterodimers and are highly dynamic polymers. Taxol stabilizes this dynamicity by binding to and altering the conformation of the microtubules. Taxol was also found to reduce the binding of microtubuleassociated proteins (MAPs). Despite the fact that MAP binding induces conformational rearrangements of $\alpha$ - and $\beta$-tubulin that promote an overall stabilization of microtubules, Taxol binding to the MAP-microtubule complex leads to further stabilization of this complex (Xiao et al., 2012). These disturbances in microtubule lead to prevention of normal mitotic spindle formation and function resulting in prevention of mitosis and thus cell proliferation (Bharadwaj and Yu, 2004; Hait et al., 2007; Ganguly et al., 2010; Malik et al., 2011; Priyadarshini and Aparajitha, 2012).

A common problem observed in Taxol-treated patients is development of drug-resistance over time. However, a combined treatment of Taxol together with down-regulation of expression of Bcl-2 (B-cell lymphoma 2), a cell death regulator, or other apoptotic related genes inhibits invasion, angiogenesis tumor growth, and maintains Taxol sensitivity in different types of cancer cells (George et al., 2009; Yang et al., 2010; Zhou et al., 2010; Maraz et al., 2011; Sun et al., 2011; Korbakis and Scorilas, 2012; Shajahan et al., 2012; Morales-Cano et al., 2013).

Although discovered in the early 1970s of the twentieth century, it took over 25 years to bring Taxol to the market. It was approved by the Food and Drug Administration (FDA) only in 1992 for the treatment of metastatic ovarian cancer. Clinical trials also demonstrated encouraging results for other cancer types such a head, neck, lung, and breast cancer (Suffness, 1995; Gordaliza, 2007). This anti-cancer drug, that is now produced in a semisynthetically (see below) process reached the list of the top-selling 20 drugs and sold above \$1 billion yearly in 1999 (Kingston, 2000;
Kinghorn, 2001; Malik et al., 2011) with a peak of $\$ 1.6$ billion in 2000 before generic drugs appeared in the market (Dwivedi et al., 2010; Buchwald-Werner and Bischoff, 2011). In 2002, sales for Taxol and Camptothecin, a DNA Topoisomerase I inhibitor, were more than $\$ 2.75$ billion, approximately a third of the anti-cancer drug market. Docetaxel (Taxotere), Taxol's analog, had sales of $\$ 3$ billion in 2009 (Demain and Vaishnav, 2011). Taxol's success serves as an example and encouraging story for discovery and bringing to market additional plant-derived substances.

Chemoprevention represents a different attitude in the battle against cancer. This approach was defined by (Sporn et al., 1976; Sharma et al., 2005; Johnson and Mukhtar, 2007) as ingestion of dietary or pharmaceutical compounds in order to prevent or delay carcinogenic processes. Many potential chemopreventive secondary metabolites in both plant extracts as well as purified molecules isolated from teas, herbs, spices, fruits and vegetables have been explored (Kelloff et al., 1994; Kinghorn, 2001).

Curcumin (diferuloylmethane) is the most prominent chemopreventive agent studied. This yellow-orange turmeric powder, is a polyphenol that accumulates in the rhizome of Curcuma longa. Both TCM and TIM have used curcumin as a medicine for treatments of diseases (Aggarwal et al., 2003; Sharma et al., 2005; Jackson et al., 2013; Thangapazham et al., 2013). Due to its capabilities to regulated important transcription factors, cytokines, protein kinases, adhesion molecules and redox status, curcumin can serve as an anti-inflammatory, anti-oxidant, anti-proliferative, anti-angiogenic, and antineoplastic agent. Thus it has been used to treat many different conditions such as neurodegenerative diseases, cardiovascular diseases, diabetes, allergy, asthma and bronchitis, inflammatory bowel diseases, rheumatoid arthritis, renal ischemia, psoriasis, scleroderma, acquired immunodeficiency disease (AIDS), and cancer as well as an anti-aging and scar formation agent (Aggarwal et al., 2003; Anand et al., 2007; Gordaliza, 2007; Johnson and Mukhtar, 2007; Aggarwal and Harikumar, 2009; Thangapazham et al., 2013).

Hundreds of studies on curcumin anti-cancer activities were published and are discussed here only briefly. Both in vitro and in vivo assays have shown inhibition of cell growth in many types of cancerous cells (Anand et al., 2008; Kunnumakkara et al., 2008). Maybe one of the most important features related to curcumin is the suppression of the transcription factor NF- $\mathrm{K}-\mathrm{B}$, a central protein in many types of cancer (Marín et al., 2007). This inhibition causes reduction in expression of NF-к-B target genes such as COX-2 and cyclin D1 resulting in apoptosis (Aggarwal et al., 2003; Thangapazham et al., 2013). Induction of apoptosis by curcumin was also shown recently when this substance was given together with the estrogen receptor antagonist Tamoxifen for treatment of melanoma. Interestingly, also autophagy was induced using such combination (Cao et al., 2007; Chatterjee and Pandey, 2011).

Curcumin can act also as chemopreventive agent of photocarcinogenesis by protecting the skin through diminishing oxidative stress and suppressing inflammation (Aggarwal et al., 2003; Heng, 2010). As Taxol, curcumin has also been shown to affect microtubule assembly leading cells to mitotic arrest (Gupta et al., 2006). Recently, this type of action by curcumin was found non-specific only to cancer cells implying its possible impact 
also on normal cells (Jackson et al., 2013). Therefore, additional studies to assure this plant-derived substance influence on normal cells and its used in combination with other anti-cancer drugs are required.

Cannabis sativa has also been used in the TCM, mainly to treat malaria, constipation, rheumatic pains and during childbirth. It was only in the nineteenth century that an Irish scientist and physician, O'Shaughnessy had found that in India it is used as an analgesic, anticonvulsant, antispasmodic, anti-emetic, and hypnotic agent. These observations caused its spreading into Europe and US, until it was outlawed in 1928 and 1937, respectively due to its negative effects (reviewed in Robson, 2001).

The plant Cannabis sativa is known to contain more than 60 terpenophenolic compounds, named phytocannabinoids (Mechoulam et al., 2002; Russo and Guy, 2006; Alexander et al., 2008; Pertwee, 2008). The first active compound isolated from Cannabis sativa was $\Delta^{9}$-tetrahydrocannabinol $\left(\Delta^{9}-\mathrm{THC}\right)$, the active component of marijuana (Gaoni and Mechoulam, 1964). Cannabinoids are mainly used in the last two centuries as supporting drugs for patients that receive either radiation or chemotherapies. These drugs ease common symptom and side effects related to such treatments as nausea, vomiting, cachexia, and loss of appetite (Robson, 2001; Tramèr et al., 2001; Hall et al., 2005; Massa et al., 2005; Massa and Monory, 2006; Grotenhermen and Müller-Vahl, 2012).

Both natural and synthetic cannabinoids act by interacting with two specific G-protein-coupled cannabinoid receptors, known as cannabinoid type 1 receptor $\left(\mathrm{CB}_{1}\right.$ receptor) and cannabinoid type 2 receptor $\left(\mathrm{CB}_{2}\right.$ receptor). The role of $\mathrm{CB}_{1}$ receptors in regulation of neurotransmitter release and its involvement in cannabinoid psychoactive effects is well known. In accordance, these receptors are positioned in central and peripheral nerves (Massa and Monory, 2006; Matias and Di Marzo, 2006; Howlett et al., 2010; Pertwee et al., 2010; Smith et al., 2010; Stella, 2010; Turu and Hunyady, 2010). On the hand, the function of $\mathrm{CB}_{2}$ receptors which are most abundant in the immune system remained vague for many years although there were evidences for their participation in regulation of cytokine's function and release (Massa and Monory, 2006; Matias and Di Marzo, 2006). Today there is enough data indicating $\mathrm{CB}_{2}$ role's in a variety of immunological functional responses mainly through progression of inflammation events. Participation of $\mathrm{CB}_{2}$ in different signal transduction pathways implies its essential function in maintenance of a homeostatic immune balance (Cabral and Griffin-Thomas, 2009; Mukhopadhyay et al., 2010; Roche and Finn, 2010). In addition, in several different studies, expression of $\mathrm{CB}_{2}$ at different levels has been also detected in the central nervous system and brain (Onaivi, 2011). Moreover, some studies indicate this receptor can be used as a selective molecular target for therapeutic treatments of both inflammationrelated conditions and neuropathic diseases that display hyperinflammation processes (Cabral and Griffin-Thomas, 2009; Atwood and Mackie, 2010; Cencioni et al., 2010; García-Gutiérrez et al., 2010; Atwood et al., 2012).

The discovery of $\Delta^{9}$-THC receptors, led to the assumption that endogenous ligands similar to this molecule should exits. Indeed, two of these ligands, anandamide and 2-arachidonoyl glycerol (2-AG), were exposed shortly after. This was followed by identification of other endogenous ligands as well as synthetic pathways responsible for both synthesis and degradation of these cannabinoids (Kogan and Mechoulam, 2006; Massa and Monory, 2006; Cabral and Griffin-Thomas, 2009; Atwood and Mackie, 2010; Pertwee et al., 2010; Stella, 2010; Onaivi, 2011).

The use of cannabinoids as anti-cancer agents is still under debate due to both cancer promoting and inhibiting effects shown in the last centuries (Hall et al., 2005; Massa et al., 2005; Velasco et al., 2015). The fact that cannabinoids play a role in cell fate decision, proliferation, and apoptosis (Guzmán et al., 2001) might imply different effects under different conditions Ligresti et al. (2003) demonstrated that the endocannabinoid system may play a role in cancer differentiation (by decreasing the levels of endogenous agonists in differentiated cells vs. undifferentiated ones), cell growth and cell migration leading to metastases. On the other hand, their results imply that in the gastrointestinal system cannabinoid receptors are involved in inhibition of cell proliferation of colorectal carcinoma (Ligresti et al., 2003; Massa and Monory, 2006). In studies using cell lines, the antineoplastic effect of both natural and synthetic cannabinoids, cannabinoids agonist, and endocannabinoids have been shown for several cancer types including carcinomas (skin, lung, prostate, and uterine), neuroblastoma, gliomas, lymphomas, thyroid epithelioma, and breast cancer. Although the mode of action leading to these effect is not completely clear, cannabinoids receptors appear to mediate it (reviewed in Hall et al., 2005; Oesch and Gertsch, 2009; Sharma et al., 2014; Velasco et al., 2015). In contrast to these in vitro studies, long-term exposure to cannabis carcinogens during smoking may lead to cancer in the aero-digestive tract and lungs (Hall et al., 2005; Aldington et al., 2008), suggesting that cannabinoids should be administrated with caution.

\section{Development and Use of Synthetic Analogs to Plant Derived Substances}

One limiting trait related to many plant secondary metabolites is their poor solubility or poor bioavailability that delays manufacturing of large amounts required to serve as medicines (Lipinski et al., 1997). The main solution adopted for different plant derived substances is the use of semi-synthetic or synthetic analogs. One known example is morphine that has been modified (to morphine-6-glucuronide) in order to obtain better therapeutics features such as side effect (Lötsch and Geisslinger, 2001).

In the case of Taxol, in addition to the low amounts produced in all Taxus species (Castor and Tyler, 1993; Kingston, 2001; Parc et al., 2002; Yazdani et al., 2005) this compound is insoluble in water (Kingston, 2000, 2001). Several different approaches were explored in attempts to obtained higher amounts of Taxol. At the end of the twentieth century, two groups reported that needles of the European Taxus, Taxus baccata L., contain a high concentration of two Taxol precursors, 10-deacetylbaccatin III and baccatin (Denis et al., 1988; Guenard et al., 1993). In addition, plant tissues culture and several semisynthetic approaches were 
tested in order to produce higher amounts of Taxol. The main step forward was achieved by combining the use of 10-deacetylbaccatin III and a semisynthetic process for production of the drug. Today, Taxol and its semisynthetic soluble analog Docetaxel (Taxotere ${ }^{\mathrm{TM}}$ ) are manufactured in a multi-step semisynthetic process, however additional improvements are needed in order to reach future market demands of this important drug (Kingston, 2001; Parc et al., 2002; Guo et al., 2006; Malik et al., 2011).

Similarly to Taxol, also curcumin is insoluble in water. In addition, due to reduced absorption in liver and in intestinal walls and systemic elimination, curcumin has poor bioavailability (Aggarwal et al., 2003; Sharma et al., 2005) that has been mainly related to rapid metabolism, fast systemic elimination and poor absorption (Anand et al., 2007). Therefore, curcumin analogs have been prepared and their capability to retain therapeutic activities has been tested. One of the main modifications applied was the change of the beta-diketone in curcumin to a monocarbonyl dienone. These analogs demonstrated good bioavailability and therapeutic effect in rodents (Gordaliza, 2007; Mosley et al., 2007). At least two other approaches to increase curcumin's bioavailability are being explored. The first approach takes advantage of adjuvants given with curcumin, that will block its metabolic pathways and/or increase its permeability resulting in higher blood concentrations and increase in its bioavailability (Anand et al., 2007; Basnet and Skalko-Basnet, 2011), while the second technique deals with new formulations of curcumin using nanoparticles (Anand et al., 2010; Basniwal et al., 2011; Chang et al., 2013), liposomes (Sun et al., 2010; Dhule et al., 2012), micelles (Hong et al., 2011; Song et al., 2011; Yang et al., 2012), and phospholipid complexes (Ghosh et al., 2011; Gupta and Dixit, 2011).

Modifications, formulations and synthetic compounds were also developed for the Cannabis derived cannabinoid $\Delta^{9}$-THC (Kogan and Mechoulam, 2006). One example is cannabidiol (CBD) another natural cannabinoid from Cannabis sativa and the major component of Sativex, a drug for multiple sclerosis and cancer pain. This cannabinoid has low affinity to $\mathrm{CB}_{1}$ and $\mathrm{CB}_{2}$ and therefore has reduced psychotropic effects (McPartland et al., 2007; Capasso et al., 2008) and it is prescribed in several European countries. Synthetic capsules of a different drug, Dronabinol, with $\Delta^{9}$-tetrahydrocannabinol as its main compound has been available in the US since 1985, while Nabilone that is a THC synthetic analog became available in 1983. Today, these drugs are also available in other countries (Robson, 2001; Tramèr et al., 2001; Howlett et al., 2010; Grotenhermen and Müller-Vahl, 2012).

Moreover, the endocannabinoid system is highly selective and has temporal specificity of activation. In the central nerve system they are not stored in vesicles but release on-demand from membrane precursors. In non-neuronal organs their expression is spatial and limited and condition-specific (Massa et al., 2005; Massa and Monory, 2006). For affecting different organs and have different activities development of different analogs and formulation for different conditions might be required.

Strigolactones (SLs) are a new potent group of plant hormones that might serve as anti-cancer drugs. These plant hormones were first identified about 50 years ago as germination stimulants of the parasitic plants Striga and Orobanche (Cook et al., 1966; reviewed in Xie et al., 2010). This family of terpenoid lactones is synthesized through the carotenoid synthesis pathway. Their molecular backbone is built from an $\mathrm{ABC}$ ring system that is connected to a butenolide through an enol ether bridge (Matusova et al., 2005; Xie et al., 2010). Moreover, SLs act in other developmental processes across the plants such as suppressors of outgrowth of pre-formed axillary shoot buds (Gomez-Roldan et al., 2008; Umehara et al., 2008), and regulators of root development (Kapulnik et al., 2011; Ruyter-Spira et al., 2011). Different plants produce different SLs and so far approximately 15 of these hormones have been structurally characterized. Further, synthetic analogs have been produced in different laboratories (reviewed by Koltai and Prandi, 2014).

Pollock et al. (2012) were the first to demonstrate the effect of SLs on cancer cells. Six SLs analogs were shown to inhibit growth and survival of breast cancer cell lines. All six analogs induced G2/M arrest but differ in extent of apoptosis. Growth inhibition in normal cells treated with these analogs was observed only with the highest SL concentration used, suggesting a dose response to these molecules. In a subsequent study (Pollock et al., 2014), inhibition was observed in both solid and non-solid cancer cells such as colon, lung, prostate, melanoma, osteosarcoma, and leukemic cell lines. Moreover, SLs were shown to act as new anti-cancer agents in inhibition of breast cancer in xenograft model with low toxicity (Mayzlish-Gati et al., 2015). Although the complete mode of action has not been revealed yet, it was shown that the tested cancer cells are arrested at G2 through activation of the p38 and JNK1/2 MAPKs causing stress induction (Pollock et al., 2012, 2014). In addition, SLs affect the integrity of the microtubule network and therefore may inhibit the migratory phenotype of the highly invasive breast cancer cell lines that were examined (Mayzlish-Gati et al., 2015).

These results suggest that SLs are potent and promising anticancer agents that induce cell cycle arrest, cellular stress and apoptosis in cancer cells. Furthermore, the variety of SLs available in nature from different plants enables development of different analogs for a large range of cancer treatments and possibly other pathological conditions and/or personalized treatments.

\section{Commercial Considerations and Future Prospects}

The traditional belief that a single drug, "silver bullet" is sufficient to treat a single disease has been questioned. This belief relies on the premise that human diseases have a uniform underlying genetic basis across patient's populations. However, recent advances in genomics demonstrate genetic diversity, i.e., polymorphism, implying that different patient populations may require different tailored drugs to their treatment, as personalized medicine. Moreover, the shortage in successful new chemical entities together with a focus of the pharmaceutical industry on such molecules to serve as "silver bullets" and the shift of companies from unpredictable research to a more steady businesses and revenues had created a crisis and loss of faith of public opinion in "silver bullets." 
The use of herbal medicines offers a way to alleviate this crisis in drug development. There are three main advances for herbal medicine: (1) utilizing the traditional herbal medicine knowledge may give rise to an inexpensive and more rapid discovery of new drugs; (2) herbal remedies offer a holistic approach that complements the disease targeted approach of "Silver bullets"; (3) synergy between the various components of the herbs which are an important element of their overall medical effects (Li, 2002).

The main disadvantage related to herbal medicines is the lack of international standardization in terms of methods for evaluating their composition, efficacy, safety, and quality, consistent manufacturing practices, regulation and approval processes. Ironically, vast knowledge and experience in drug development is available in the pharmaceutical industry. Therefore, combining the benefits provided by both traditional and modern medicine

\section{References}

Aggarwal, B. B., and Harikumar, K. B. (2009). Potential therapeutic effects of curcumin, the anti-inflammatory agent, against neurodegenerative, cardiovascular, pulmonary, metabolic, autoimmune and neoplastic diseases. Int. J. Biochem. Cell Biol. 41, 40-59. doi: 10.1016/j.biocel.2008.06.010

Aggarwal, B. B., Kumar, A., and Bharti, A. C. (2003). Anticancer potential of curcumin: preclinical and clinical studies. Anticancer. Res. 23, 363-398.

Aldington, S., Harwood, M., Cox, B., Weatherall, M., Beckert, L., Hansell, A., et al. (2008). Cannabis use and risk of lung cancer: a case-control study. Eur. Respir. J. 31, 280-286. doi: 10.1183/09031936.00065707

Alexander, S. P., Mathie, A., and Peters, J. A. (2008). Guide to receptors and channels (GRAC). Br. J. Pharmacol. 153, S1-S1. doi: 10.1038/sj.bjp.0707746

Anand, P., Kunnumakkara, A. B., Newman, R. A., and Aggarwal, B. B. (2007). Bioavailability of curcumin: problems and promises. Mol. Pharm. 4, 807-818. doi: $10.1021 / \mathrm{mp} 700113 \mathrm{r}$

Anand, P., Nair, H. B., Sung, B., Kunnumakkara, A. B., Yadav, V. R., Tekmal, R. R., et al. (2010). Design of curcumin-loaded PLGA nanoparticles formulation with enhanced cellular uptake, and increased bioactivity in vitro and superior bioavailability in vivo. Biochem. Pharmacol. 79, 330-338. doi: 10.1016/j.bcp.2009.09.003

Anand, P., Sundaram, C., Jhurani, S., Kunnumakkara, A. B., and Aggarwal, B. B. (2008). Curcumin and cancer: an "old-age" disease with an "age-old" solution. Cancer Lett. 267, 133-164. doi: 10.1016/j.canlet.2008.03.025

Atwood, B. K., and Mackie, K. (2010). $\mathrm{CB}_{2}$ : a cannabinoid receptor with an identity crisis. Br. J. Pharmacol. 160, 467-479. doi: 10.1111/j.1476-5381.2010.00729.x

Atwood, B. K., Wager-Miller, J., Haskins, C., Straiker, A., and Mackie, K. (2012). Functional selectivity in $\mathrm{CB}_{2}$ cannabinoid receptor signaling and regulation: implications for the therapeutic potential of $\mathrm{CB}_{2}$ ligands. Mol. Pharmacol. 81, 250-263. doi: 10.1124/mol.111.074013

Awad, N., Kassem, H., Hamed, M., El-Naggar, M., and El-Feky, A. (2014). Bioassays guided isolation of compounds from Chaetomium globosum. J. Med. Mycol. 24, e35-e42. doi: 10.1016/j.mycmed.2013.10.005

Balick, M. J., and Cox, P. A. (1996). Plants, People, and Culture: the Science of Ethnobotany. New York: Scientific American Library.

Balunas, M. J., and Kinghorn, A. D. (2005). Drug discovery from medicinal plants. Life Sci. 78, 431-441. doi: 10.1016/j.lfs.2005.09.012

Basnet, P., and Skalko-Basnet, N. (2011). Curcumin: an anti-inflammatory molecule from a curry spice on the path to cancer treatment. Molecules 16, 4567-4598. doi: 10.3390/molecules16064567

Basniwal, R. K., Buttar, H. S., Jain, V., and Jain, N. (2011). Curcumin nanoparticles: preparation, characterization, and antimicrobial study. J. Agric. Food Chem. 59, 2056-2061. doi: 10.1021/jf104402t

Bharadwaj, R., and Yu, H. (2004). The spindle checkpoint, aneuploidy, and cancer. Oncogene 23, 2016-2027. doi: 10.1038/sj.onc.1207374

Buchwald-Werner, S., and Bischoff, F. (2011). "Natural products-market development and potentials," in Industrial scale natural products extraction. eds H.-J. Bart and S. Pilz (Wiley-VCH Verlag GmbH), 247-267. doi: $10.1002 / 9783527635122 . c h 8$ has been previously suggested as a promising approach in order to reveal and bring to market new plant-derived substances. However, in the last centuries only several herbal medicines or botanical drugs have been approved by health authorities for human use (Calixto, 2000; Li, 2002; Liu and Wang, 2008; Schmidt et al., 2008; Patwardhan and Mashelkar, 2009; Graziose et al., 2010; Sahoo et al., 2010; Choudhary and Sekhon, 2011; Newman and Cragg, 2012). Collaboration and coordination between World Health Organization (WHO), Federal Drug Administration (FDA), European and other regulatory agencies, and the pharmaceutical industry worldwide may lead to clear guidance for development of herbal medications while taking advantage of the huge potential held by traditional medicine for development of both anti-cancer and other health promoting drugs.

Butler, M. S. (2004). The role of natural product chemistry in drug discovery. J. Nat. Prod. 67, 2141-2153. doi: 10.1021/np040106y

Cabral, G. A., and Griffin-Thomas, L. (2009). Emerging role of the cannabinoid receptor $\mathrm{CB}_{2}$ in immune regulation: therapeutic prospects for neuroinflammation. Expert Rev. Mol. Med. 11, e3. doi: 10.1017/S14623994 09000957

Calixto, J. B. (2000). Efficacy, safety, quality control, marketing and regulatory guidelines for herbal medicines (phytotherapeutic agents). Braz. J. Med. Biol. Res. 33, 179-189. doi: 10.1590/S0100-879X2000000200004

Cao, J., Liu, Y., Jia, L., Zhou, H.-M., Kong, Y., Yang, G., et al. (2007). Curcumin induces apoptosis through mitochondrial hyperpolarization and mtDNA damage in human hepatoma G2 cells. Free Radic. Biol. Med. 43, 968-975. doi: 10.1016/j.freeradbiomed.2007.06.006

Capasso, R., Borrelli, F., Aviello, G., Romano, B., Scalisi, C., Capasso, F., et al. (2008). Cannabidiol, extracted from Cannabis sativa, selectively inhibits inflammatory hypermotility in mice. Br. J. Pharmacol. 154, 1001-1008. doi: 10.1038/bjp.2008.177

Castor, T. P., and Tyler, T. A. (1993). Determination of taxol in Taxus media needles in the presence of interfering components. J. Liq. Chromatogr. Relat. Technol. 16, 723-731. doi: 10.1080/10826079308019559

Cencioni, M. T., Chiurchiù, V., Catanzaro, G., Borsellino, G., Bernardi, G., Battistini, L., et al. (2010). Anandamide suppresses proliferation and cytokine release from primary human T-lymphocytes mainly via $\mathrm{CB}_{2}$ receptors. PLoS ONE 5:e8688. doi: 10.1371/journal.pone.0008688

Chandra, S. (2012). Endophytic fungi: novel sources of anticancer lead molecules. Appl. Microbiol. Biotechnol. 95, 47-59. doi: 10.1007/s00253-012-4128-7

Chang, P.-Y., Peng, S.-F., Lee, C.-Y., Lu, C.-C., Tsai, S.-C., Shieh, T.-M., et al. (2013). Curcumin-loaded nanoparticles induce apoptotic cell death through regulation of the function of MDR1 and reactive oxygen species in cisplatin-resistant CAR human oral cancer cells. Int. J. Oncol. 43, 1141-1150. doi: 10.3892/ijo.2013. 2050

Chatterjee, S. J., and Pandey, S. (2011). Chemo-resistant melanoma sensitized by tamoxifen to low dose curcumin treatment through induction of apoptosis and autophagy. Cancer Biol. Ther. 11, 216-228. doi: 10.4161/cbt.11.2.13798

Chin, Y.-W., Balunas, M. J., Chai, H. B., and Kinghorn, A. D. (2006). Drug discovery from natural sources. AAPS J. 8, E239-E253. doi: 10.1007/BF02854894

Choudhary, N., and Sekhon, B. S. (2011). An overview of advances in the standardization of herbal drugs. J. Pharm. Educ. Res. 2, 55-70.

Cook, C., Whichard, L. P., Turner, B., Wall, M. E., and Egley, G. H. (1966). Germination of witchweed (Striga lutea Lour.): isolation and properties of a potent stimulant. Science 154, 1189-1190. doi: 10.1126/science.154.3753.1189

Deleu, D., Hanssens, Y., and Northway, M. (2004). Subcutaneous apomorphine. An evidence-based review of its use in Parkinson's disease. Drugs Aging 21, 687-709. doi: 10.2165/00002512-200421110-00001

Demain, A. L., and Vaishnav, P. (2011). Natural products for cancer chemotherapy. Microb. Biotechnol. 4, 687-699. doi: 10.1111/j.1751-7915.2010.00221.x

Denis, J. N., Greene, A. E., Guenard, D., Gueritte-Voegelein, F., Mangatal, L., and Potier, P. (1988). Highly efficient, practical approach to natural taxol. J. Am. Chem. Soc. 110, 5917-5919. doi: 10.1021/ja00225a063 
DeSantis, C. E., Lin, C. C., Mariotto, A. B., Siegel, R. L., Stein, K. D., Kramer, J. L., et al. (2014). Cancer treatment and survivorship statistics, 2014. CA Cancer J. Clin. 64, 252-271. doi: 10.3322/caac.21235

Dhule, S. S., Penfornis, P., Frazier, T., Walker, R., Feldman, J., Tan, G., et al. (2012). Curcumin-loaded $\gamma$-cyclodextrin liposomal nanoparticles as delivery vehicles for osteosarcoma. Nanomedicine 8, 440-451. doi: 10.1016/j.nano.2011.07.011

Dwivedi, G., Hallihosur, S., and Rangan, L. (2010). Evergreening: a deceptive device in patent rights. Technol. Soc. 32, 324-330. doi: 10.1016/j.techsoc.2010.10.009

Elbaz, H. A., Stueckle, T. A., Tse, W., Rojanasakul, Y., and Dinu, C. Z. (2012). Digitoxin and its analogs as novel cancer. Exp. Hematol. Oncol. 1, 4. doi: 10.1186/2162-3619-1-4

Ganguly, A., Yang, H., and Cabral, F. (2010). Paclitaxel-dependent cell lines reveal a novel drug activity. Mol. Cancer Ther. 9, 2914-2923. doi: 10.1158/15357163.MCT-10-0552

Gaoni, Y., and Mechoulam, R. (1964). Isolation, structure, and partial synthesis of an active constituent of hashish. J. Am. Chem. Soc. 86, 1646-1647. doi: 10.1021/ja01062a046

García-Gutiérrez, M. S., Pérez-Ortiz, J. M., Gutiérrez-Adán, A., and Manzanares, J. (2010). Depression-resistant endophenotype in mice overexpressing cannabinoid $\mathrm{CB}_{2}$ receptors. Br. J. Pharmacol. 160, 1773-1784. doi: 10.1111/j.1476-5381.2010.00819.x

George, J., Banik, N. L., and Ray, S. K. (2009). Combination of taxol and Bcl-2 siRNA induces apoptosis in human glioblastoma cells and inhibits invasion, angiogenesis and tumour growth. J. Cell. Mol. Med. 13, 4205-4218. doi: 10.1111/j.1582-4934.2008.00539.x

Ghosh, M., Singh, A. T., Xu, W., Sulchek, T., Gordon, L. I., and Ryan, R. O. (2011). Curcumin nanodisks: formulation and characterization. Nanomedicine 7, 162-167. doi: 10.1016/j.nano.2010.08.002

Goldman, P. (2001). Herbal medicines today and the roots of modern pharmacology. Ann. Intern. Med. 135, 594-600. doi: 10.7326/0003-4819135-8_Part_1-200110160-00010

Gomez-Roldan, V., Fermas, S., Brewer, P. B., Puech-Pagès, V., Dun, E. A., Pillot, J.-P., et al. (2008). Strigolactone inhibition of shoot branching. Nature 455, 189-194. doi: 10.1038/nature07271

Gordaliza, M. (2007). Natural products as leads to anticancer drugs. Clin. Transl. Oncol. 9, 767-776. doi: 10.1007/s12094-007-0138-9

Graul, A. I. (2004). The year's new drugs. Drug News Perspect. 17, 43-57.

Graziose, R., Lila, M. A., and Raskin, I. (2010). Merging traditional Chinese medicine with modern drug discovery technologies to find novel drugs and functional foods. Curr. Drug Discov. Technol. 7, 2. doi: $10.2174 / 157016310791162767$

Grotenhermen, F., and Müller-Vahl, K. (2012). The therapeutic potential of cannabis and cannabinoids. Deutsch. Ärztebl. Int. 109, 495. doi: 10.3238/arztebl.2012.0495

Guenard, D., Gueritte-Voegelein, F., and Potier, P. (1993). Taxol and taxotere: discovery, chemistry, and structure-activity relationships. Acc. Chem. Res. 26, 160-167. doi: 10.1021/ar00028a005

Guo, B., Kai, G., Jin, H., and Tang, K. (2006). Review-Taxol synthesis. Afr. J. Biotechnol. 5, 15-20.

Gupta, K. K., Bharne, S. S., Rathinasamy, K., Naik, N. R., and Panda, D. (2006). Dietary antioxidant curcumin inhibits microtubule assembly through tubulin binding. FEBS J. 273, 5320-5332. doi: 10.1111/j.1742-4658.2006.05525.x

Gupta, N. K., and Dixit, V. K. (2011). Bioavailability enhancement of curcumin by complexation with phosphatidyl choline. J. Pharm. Sci. 100, 1987-1995. doi: 10.1002/jps.22393

Guzmán, M., Sánchez, C., and Galve-Roperh, I. (2001). Control of the cell survival/death decision by cannabinoids. J. Mol. Med. 78, 613-625. doi: 10.1007/s001090000177

Hait, W. N., Rubin, E., Alli, E., and Goodin, S. (2007). Tubulin targeting agents. Update Cancer Ther. 2, 1-18. doi: 10.1016/j.uct.2006.10.001

Hall, M. G., Wilks, M. F., Provan, W. M., Eksborg, S., and Lumholtz, B. (2001). Pharmacokinetics and pharmacodynamics of NTBC (2-(2-nitro-4fluoromethylbenzoyl)-1,3-cyclohexanedione) and mesotrione, inhibitors of 4hydroxyphenyl pyruvate dioxygenase (HPPD) following a single dose to healthy male volunteers. Br. J. Clin. Pharmacol. 52, 169-177. doi: 10.1046/j.03065251.2001.01421.x

Hall, W., Christie, M., and Currow, D. (2005). Cannabinoids and cancer: causation, remediation, and palliation. Lancet Oncol. 6, 35-42. doi: 10.1016/S14702045(04)01711-5
Heinrich, M., and Teoh, H. L. (2004). Galanthamine from snowdrop-the development of a modern drug against Alzheimer's disease from local Caucasian knowledge. J. Ethnopharmacol. 92, 147-162. doi: 10.1016/j.jep.2004.02.012

Heng, M. C. (2010). Curcumin targeted signaling pathways: basis for antiphotoaging and anti-carcinogenic therapy. Int. J. Dermatol. 49, 608-622. doi: $10.1111 /$ j.1365-4632.2010.04468.x

Hong, D. W., Liu, T. H., and Chu, I. (2011). Encapsulation of curcumin by methoxy poly (ethylene glycol-b-aromatic anhydride) micelles. J. Appl. Polym. Sci. 122, 898-907. doi: 10.1002/app.34191

Howlett, A. C., Blume, L. C., and Dalton, G. D. (2010). $\mathrm{CB}_{1}$ cannabinoid receptors and their associated proteins. Curr. Med. Chem 17, 1382. doi: $10.2174 / 092986710790980023$

Jackson, S. J., Murphy, L. L., Venema, R. C., Singletary, K. W., and Young, A. J. (2013). Curcumin binds tubulin, induces mitotic catastrophe, and impedes normal endothelial cell proliferation. Food Chem. Toxicol. 60, 431-438. doi: 10.1016/j.fct.2013.08.008

Johnson, J. J., and Mukhtar, H. (2007). Curcumin for chemoprevention of colon cancer. Cancer Lett. 255, 170-181. doi: 10.1016/j.canlet.2007.03.005

Kapulnik, Y., Delaux, P.-M., Resnick, N., Mayzlish-Gati, E., Wininger, S., Bhattacharya, C., et al. (2011). Strigolactones affect lateral root formation and root-hair elongation in Arabidopsis. Planta 233, 209-216. doi: 10.1007/s00425010-1310-y

Kaul, S., Gupta, S., Ahmed, M., and Dhar, M. K. (2012). Endophytic fungi from medicinal plants: a treasure hunt for bioactive metabolites. Phytochem. Rev. 11, 487-505. doi: 10.1007/s11101-012-9260-6

Kelloff, G. J., Boone, C. W., Crowell, J. A., Steele, V. E., Lubet, R., and Sigman, C. C. (1994). Chemopreventive drug development: perspectives and progress. Cancer Epidemiol. Biomarkers Prev. 3, 85-98.

Kennedy, R. K., Naik, P. R., Veena, V., Lakshmi, B., Lakshmi, P., Krishna, R., et al. (2015). 5-Methyl phenazine-1-carboxylic acid: a novel bioactive metabolite by a rhizosphere soil bacterium that exhibits potent antimicrobial and anticancer activities. Chem. Biol. Interact. 231, 71-82. doi: 10.1016/j.cbi.2015. 03.002

Kinghorn, A. D. (2001). Pharmacognosy in the 21st century. J. Pharm. Pharmacol. 53, 135-148. doi: 10.1211/0022357011775334

Kingston, D. G. (2000). Recent advances in the chemistry of taxol. J. Nat. Prod. 63, 726-734. doi: 10.1021/np000064n

Kingston, D. G. (2001). Taxol, a molecule for all seasons. Chem. Commun. 10, 867-880. doi: 10.1039/b100070p

Kogan, N., and Mechoulam, R. (2006). The chemistry of endocannabinoids. J. Endocrinol. Invest. 29, 3-14.

Koltai, H., and Prandi, C. (2014). "Strigolactones: biosynthesis, synthesis and functions in plant growth and stress responses," in Phytohormones: A Window to Metabolism, Signaling and Biotechnological Applications eds Lam-Son Phan Tran and Sikander Pal. (New York: Springer), 265-288.

Korbakis, D., and Scorilas, A. (2012). Quantitative expression analysis of the apoptosis-related genes BCL2, BAX and BCL2L12 in gastric adenocarcinoma cells following treatment with the anticancer drugs cisplatin, etoposide and taxol. Tumor Biol. 33, 865-875. doi: 10.1007/s13277-011-0313-z

Koumis, T., and Samuel, S. (2005). Tiotropium bromide: a new long-acting bronchodilator for the treatment of chronic obstructive pulmonary disease. Clin. Ther. 27, 377-392. doi: 10.1016/j.clinthera.2005.04.006

Kunnumakkara, A. B., Anand, P., and Aggarwal, B. B. (2008). Curcumin inhibits proliferation, invasion, angiogenesis and metastasis of different cancers through interaction with multiple cell signaling proteins. Cancer Lett. 269, 199-225. doi: 10.1016/j.canlet.2008.03.009

Li, W. (2002). Botanical Drugs: The Next New New Thing? Available at: http://nrs.harvard.edu/urn-3:HUL.InstRepos:8965577 (accessed September 26, 2015).

Ligresti, A., Bisogno, T., Matias, I., De Petrocellis, L., Cascio, M. G., Cosenza, V., et al. (2003). Possible endocannabinoid control of colorectal cancer growth. Gastroenterology 125, 677-687. doi: 10.1016/S0016-5085(03)00881-3

Lipinski, C. A., Lombardo, F., Dominy, B. W., and Feeney, P. J. (1997). Experimental and computational approaches to estimate solubility and permeability in drug discovery and development settings. Adv. Drug Deliv. Rev. 23, 3-25. doi: 10.1016/S0169-409X(96)00423-1

Liu, Y., and Wang, M.-W. (2008). Botanical drugs: challenges and opportunities: contribution to Linnaeus Memorial Symposium 2007. Life Sci. 82, 445-449. doi: 10.1016/j.lfs.2007.11.007 
Lötsch, J., and Geisslinger, G. (2001). Morphine-6-Glucuronide. Clin. Pharmacokinet. 40, 485-499. doi: 10.2165/00003088-200140070-00001

Malik, S., Cusidó, R. M., Mirjalili, M. H., Moyano, E., Palazón, J., and Bonfill, M. (2011). Production of the anticancer drug taxol in Taxus baccata suspension cultures: a review. Process Biochem. 46, 23-34. doi: 10.1016/j.procbio.2010.09.004

Maraz, A., Furak, J., Palfoeldi, R., Eller, J., Szanto, E., Kahan, Z., et al. (2011). Roles of BCL-2 and MDR1 expression in the efficacy of paclitaxel-based lung cancer chemoradiation. Anticancer Res. 31, 1431-1436.

Marín, Y. E., Wall, B. A., Wang, S., Namkoong, J., Martino, J. J., Suh, J., et al. (2007). Curcumin downregulates the constitutive activity of NF- $\mathrm{\kappa B}$ and induces apoptosis in novel mouse melanoma cells. Melanoma Res. 17, 274-283. doi: 10.1097/CMR.0b013e3282ed3d0e

Massa, F., and Monory, K. (2006). Endocannabinoids and the gastrointestinal tract. J. Endocrinol. Invest. 29, 47-57.

Massa, F., Storr, M., and Lutz, B. (2005). The endocannabinoid system in the physiology and pathophysiology of the gastrointestinal tract. J. Mol. Med. 83, 944-954. doi: 10.1007/s00109-005-0698-5

Matias, I., and Di Marzo, V. (2006). Endocannabinoid synthesis and degradation, and their regulation in the framework of energy balance. J. Endocrinol. Invest. $29,15-26$.

Matusova, R., Rani, K., Verstappen, F. W., Franssen, M. C., Beale, M. H., and Bouwmeester, H. J. (2005). The strigolactone germination stimulants of the plant-parasitic Striga and Orobanche spp. are derived from the carotenoid pathway. Plant Physiol. 139, 920-934. doi: 10.1104/pp.105. 061382

Mayzlish-Gati, E., Laufer, D., Shaknof, J., Sananes, A., Bier, A., Ben-Harosh, S., et al. (2015). Strigolactone analogs act as new anti-cancer agents in inhibition of breast cancer in xenograft Q1 model. Cancer Biol. Ther. doi: 10.1080/15384047.2015.1070982 [Epub ahead of print].

McPartland, J., Glass, M., and Pertwee, R. (2007). Meta-analysis of cannabinoid ligand binding affinity and receptor distribution: interspecies differences. $\mathrm{Br}$. J. Pharmacol. 152, 583-593. doi: 10.1038/sj.bjp.0707399

Mechoulam, R., Parker, L. A., and Gallily, R. (2002). Cannabidiol: an overview of some pharmacological aspects. J. Clin. Pharmacol. 42, 11S-19S. doi: 10.1002/j.1552-4604.2002.tb05998.x

Menger, L., Vacchelli, E., Kepp, O., Eggermont, A., Tartour, E., Zitvogel, L., et al. (2013). Trial watch: cardiac glycosides and cancer therapy. Oncoimmunology 2 , e23082. doi: 10.4161/onci.23082

Mitchell, G., Bartlett, D. W., Fraser, T. E., Hawkes, T. R., Holt, D. C., Townson, J. K., et al. (2001). Mesotrione: a new selective herbicide for use in maize. Pest. Manag. Sci. 57, 120-128. doi: 10.1002/1526-4998(200102)57:2<120::AIDPS254>3.0.CO;2-E

Morales-Cano, D., Calvino, E., Rubio, V., Herráez, A., Sancho, P., Tejedor, M. C., et al. (2013). Apoptosis induced by paclitaxel via Bcl-2, Bax and caspases 3 and 9 activation in NB4 human leukaemia cells is not modulated by ERK inhibition. Exp. Toxicol. Pathol. 65, 1101-1108. doi: 10.1016/j.etp.2013. 04.006

Mosley, C. A., Liotta, D. C., and Snyder, J. P. (2007). "Highly active anticancer curcumin analogues," in The Molecular Targets and Therapeutic Uses of Curcumin in Health and Disease eds B. Bharat, Aggarwal, Young-Joon Surh and Shishir Shishodia. (New York: Springer), 77-103.

Mukhopadhyay, P., Rajesh, M., Pan, H., Patel, V., Mukhopadhyay, B., Bátkai, S., et al. (2010). Cannabinoid-2 receptor limits inflammation, oxidative/nitrosative stress, and cell death in nephropathy. Free Radic. Biol. Med. 48, 457-467. doi: 10.1016/j.freeradbiomed.2009.11.022

Mundy, C., and Kirkpatrick, P. (2004). Tiotropium bromide. Nat. Rev. Drug Discov. 3, 643-644. doi: 10.1038/nrd1472

Newman, D. J., and Cragg, G. M. (2012). Natural products as sources of new drugs over the 30 years from 1981 to 2010. J. Nat. Prod. 75, 311-335. doi: 10.1021/np200906s

Newman, D. J., Cragg, G. M., and Snader, K. M. (2000). The influence of natural products upon drug discovery. Nat. Prod. Rep. 17, 215-234. doi: $10.1039 / \mathrm{a} 902202 \mathrm{c}$

Oesch, S., and Gertsch, J. (2009). Cannabinoid receptor ligands as potential anticancer agents-high hopes for new therapies? J. Pharm. Pharmacol. 61, 839-853. doi: 10.1211/jpp.61.07.0002

Onaivi, E. (2011). Commentary: functional neuronal $\mathrm{CB}_{2}$ cannabinoid receptors in the CNS. Curr. Neuropharmacol. 9, 205-208. doi: 10.2174/157015911795017416
Parc, G., Canaguier, A., Landré, P., Hocquemiller, R., Chriqui, D., and Meyer, M. (2002). Production of taxoids with biological activity by plants and callus culture from selected Taxus genotypes. Phytochemistry 59, 725-730. doi: 10.1016/S00319422(02)00043-2

Patwardhan, B., and Mashelkar, R. A. (2009). Traditional medicine-inspired approaches to drug discovery: can Ayurveda show the way forward? Drug Discov. Today 14, 804-811. doi: 10.1016/j.drudis.2009.05.009

Patwardhan, B., Warude, D., Pushpangadan, P., and Bhatt, N. (2005). Ayurveda and traditional Chinese medicine: a comparative overview. Evid. Based Complement. Alternat. Med. 2, 465-473. doi: 10.1093/ecam/neh140

Pertwee, R. (2008). The diverse $\mathrm{CB}_{1}$ and $\mathrm{CB}_{2}$ receptor pharmacology of three plant cannabinoids: $\Delta^{9}$-tetrahydrocannabinol, cannabidiol and $\Delta^{9}$-tetrahydrocannabivarin. Br. J. Pharmacol. 153, 199-215. doi: 10.1038/sj.bjp.0707442

Pertwee, R., Howlett, A., Abood, M. E., Alexander, S., Di Marzo, V., Elphick, M., et al. (2010). International Union of Basic and Clinical Pharmacology. LXXIX. Cannabinoid receptors and their ligands: beyond $\mathrm{CB}_{1}$ and $\mathrm{CB}_{2}$. Pharmacol. Rev. 62, 588-631. doi: 10.1124/pr.110.003004

Pirttilä, T., Wilcock, G., Truyen, L., and Damaraju, C. (2004). Long-term efficacy and safety of galantamine in patients with mild-to-moderate Alzheimer's disease: multicenter trial. Eur. J. Neurol. 11, 734-741. doi: 10.1111/j.14681331.2004.00885.x

Pollock, C., Koltai, H., Kapulnik, Y., Prandi, C., and Yarden, R. (2012). Strigolactones: a novel class of phytohormones that inhibit the growth and survival of breast cancer cells and breast cancer stem-like enriched mammosphere cells. Breast Cancer Res. Treat. 134, 1041-1055. doi: 10.1007/s10549-012-1992-x

Pollock, C. B., Mcdonough, S., Wang, V. S., Lee, H., Ringer, L., Li, X., et al. (2014). Strigolactone analogues induce apoptosis through activation of p38 and the stress response pathway in cancer cell lines and in conditionally reprogramed primary prostate cancer cells. Oncotarget 5, 1683-1698. doi: 10.18632/oncotarget.1849

Priyadarshini, K., and Aparajitha, U. K. (2012). Paclitaxel against cancer: a short review. Med. Chem. 2, 139-141.

Prota, A. E., Bargsten, K., Zurwerra, D., Field, J. J., Díaz, J. F., Altmann, K.-H., et al. (2013). Molecular mechanism of action of microtubule-stabilizing anticancer agents. Science 339, 587-590. doi: 10.1126/science. 1230582

Robinson, M. M., and Zhang, X. (2011). The World Medicines Situation 2011. Traditional Medicines: Global Situation, Issues and Challenges. Geneva: World Health Organization.

Robson, P. (2001). Therapeutic aspects of cannabis and cannabinoids. Br. J. Psychiatry 178, 107-115. doi: 10.1192/bjp.178.2.107

Roche, M., and Finn, D. P. (2010). Brain $\mathrm{CB}_{2}$ receptors: implications for neuropsychiatric disorders. Pharmaceuticals 3, 2517-2553. doi: $10.3390 / \mathrm{ph} 3082517$

Russo, E., and Guy, G. W. (2006). A tale of two cannabinoids: the therapeutic rationale for combining tetrahydrocannabinol and cannabidiol. Med. Hypotheses 66, 234-246. doi: 10.1016/j.mehy.2005.08.026

Ruyter-Spira, C., Kohlen, W., Charnikhova, T., Van Zeijl, A., Van Bezouwen, L., De Ruijter, N., et al. (2011). Physiological effects of the synthetic strigolactone analog GR24 on root system architecture in Arabidopsis: another belowground role for strigolactones? Plant Physiol. 155, 721-734. doi: 10.1104/pp.110.166645

Ryan, R. P., Germaine, K., Franks, A., Ryan, D. J., and Dowling, D. N. (2008). Bacterial endophytes: recent developments and applications. FEMS Microbiol. Lett. 278, 1-9. doi: 10.1111/j.1574-6968.2007.00918.x

Sahoo, N., Manchikanti, P., and Dey, S. (2010). Herbal drugs: standards and regulation. Fitoterapia 81, 462-471. doi: 10.1016/j.fitote.2010.02.001

Samuelsson, G. (ed.). (2004). Drugs of Natural Origin: A Textbook of Pharmacognosy, 5th Edn. Stockholm: Swedish Pharmaceutical Press.

Schmidt, B., Ribnicky, D. M., Poulev, A., Logendra, S., Cefalu, W. T., and Raskin, I. (2008). A natural history of botanical therapeutics. Metabolism 57, S3-S9. doi: 10.1016/j.metabol.2008.03.001

Shajahan, A. N., Dobbin, Z. C., Hickman, F. E., Dakshanamurthy, S., and Clarke, R. (2012). Tyrosine-phosphorylated caveolin-1 (Tyr-14) increases sensitivity to paclitaxel by inhibiting BCL2 and BCLxL proteins via c-Jun N-terminal kinase (JNK). J. Biol. Chem. 287, 17682-17692. doi: 10.1074/jbc.M111.304022

Sharma, M., Hudson, J. B., Adomat, H., Guns, E., and Cox, M. E. (2014). In vitro anticancer activity of plant-derived cannabidiol on prostate cancer cell lines. Pharmacol. Pharm. 2014, 806-820. doi: 10.4236/pp.2014.58091 
Sharma, R., Gescher, A., and Steward, W. (2005). Curcumin: the story so far. Eur. J. Cancer 41, 1955-1968. doi: 10.1016/j.ejca.2005.05.009

Smith, T. H., Sim-Selley, L. J., and Selley, D. E. (2010). Cannabinoid $\mathrm{CB}_{1}$ receptorinteracting proteins: novel targets for central nervous system drug discovery? $\mathrm{Br}$. J. Pharmacol. 160, 454-466. doi: 10.1111/j.1476-5381.2010.00777.x

Song, L., Shen, Y., Hou, J., Lei, L., Guo, S., and Qian, C. (2011). Polymeric micelles for parenteral delivery of curcumin: preparation, characterization and in vitro evaluation. Colloids Surf. A Physicochem. Eng. Asp. 390, 25-32. doi: 10.1016/j.colsurfa.2011.08.031

Sporn, M. B., Dunlop, N., Newton, D., and Smith, J. (1976). Prevention of chemical carcinogenesis by vitamin A and its synthetic analogs (retinoids). Fed. Proc. 35, 1332-1338.

Stella, N. (2010). Cannabinoid and cannabinoid-like receptors in microglia, astrocytes, and astrocytomas. Glia 58, 1017-1030. doi: 10.1002/glia.20983

Stierle, A., Strobel, G., and Stierle, D. (1993). Taxol and taxane production by Taxomyces andreanae, an endophytic fungus of Pacific yew. Science 260, 214-216. doi: 10.1126/science.8097061

Strobel, G., and Daisy, B. (2003). Bioprospecting for microbial endophytes and their natural products. Microbiol. Mol. Biol. Rev. 67, 491-502. doi: 10.1128/MMBR.67.4.491-502.2003

Strobel, G., Daisy, B., Castillo, U., and Harper, J. (2004). Natural products from endophytic microorganisms. J. Nat. Prod. 67, 257-268. doi: 10.1021/np030397v Suffness, M. (1995). Taxol: Science and Applications. Boca Raton: CRC press.

Sun, D., Zhuang, X., Xiang, X., Liu, Y., Zhang, S., Liu, C., et al. (2010). A novel nanoparticle drug delivery system: the anti-inflammatory activity of curcumin is enhanced when encapsulated in exosomes. Mol. Ther. 18, 1606-1614. doi: $10.1038 / \mathrm{mt} .2010 .105$

Sun, T.-M., Du, J.-Z., Yao, Y.-D., Mao, C.-Q., Dou, S., Huang, S.-Y., et al. (2011). Simultaneous delivery of siRNA and paclitaxel via a "two-in-one" micelleplex promotes synergistic tumor suppression. ACS Nano 5, 1483-1494. doi: $10.1021 / \mathrm{nn} 103349 \mathrm{~h}$

Thangapazham, R. L., Sharad, S., and Maheshwari, R. K. (2013). Skin regenerative potentials of curcumin. Biofactors 39, 141-149. doi: 10.1002/biof.1078

Tramèr, M. R., Carroll, D., Campbell, F. A., Reynolds, D. J. M., Moore, R. A., and Mcquay, H. J. (2001). Cannabinoids for control of chemotherapy induced nausea and vomiting: quantitative systematic review. $B M J 323,1-8$. doi: 10.1136/bmj.323.7303.16

Turu, G., and Hunyady, L. (2010). Signal transduction of the $\mathrm{CB}_{1}$ cannabinoid receptor. J. Mol. Endocrinol. 44, 75-85. doi: 10.1677/JME-08-0190

Umehara, M., Hanada, A., Yoshida, S., Akiyama, K., Arite, T., Takeda-Kamiya, N., et al. (2008). Inhibition of shoot branching by new terpenoid plant hormones. Nature 455, 195-200. doi: 10.1038/nature07272

Van Agtmael, M. A., Eggelte, T. A., and Van Boxtel, C. J. (1999). Artemisinin drugs in the treatment of malaria: from medicinal herb to registered medication. Trends Pharmacol. Sci. 20, 199-205. doi: 10.1016/S0165-6147(99)01302-4
Velasco, G., Hernández-Tiedra, S., Dávila, D., and Lorente, M. (2015). The use of cannabinoids as anticancer agents. Prog. Neuropsychopharmacol. Biol. Psychiatry 64, 259-266. doi: 10.1016/j.pnpbp.2015.05.010

Wang, Y., Xu, L., Ren, W., Zhao, D., Zhu, Y., and Wu, X. (2012). Bioactive metabolites from Chaetomium globosum L18, an endophytic fungus in the medicinal plant Curcuma wenyujin. Phytomedicine 19, 364-368. doi: 10.1016/j.phymed.2011.10.011

Wani, M. C., Taylor, H. L., Wall, M. E., Coggon, P., and Mcphail, A. T. (1971). Plant antitumor agents. VI. Isolation and structure of taxol, a novel antileukemic and antitumor agent from Taxus brevifolia. J. Am. Chem. Soc. 93, 2325-2327. doi: $10.1021 / \mathrm{ja} 00738 \mathrm{a} 045$

Xiao, H., Verdier-Pinard, P., Fernandez-Fuentes, N., Burd, B., Angeletti, R., Fiser, A., et al. (2006). Insights into the mechanism of microtubule stabilization by Taxol. Proc. Natl. Acad. Sci. U.S.A. 103, 10166-10173. doi: 10.1073/pnas.0603704103

Xiao, H., Wang, H., Zhang, X., Tu, Z., Bulinski, C., Khrapunovich-Baine, M., et al. (2012). Structural evidence for cooperative microtubule stabilization by Taxol and the endogenous dynamics regulator MAP4. ACS Chem. Biol. 7, 744-752. doi: $10.1021 / \mathrm{cb} 200403 \mathrm{x}$

Xie, X., Yoneyama, K., and Yoneyama, K. (2010). The strigolactone story. Annu. Rev. Phytopathol. 48, 93-117. doi: 10.1146/annurev-phyto-073009-114453

Yang, J.-S., Hour, M.-J., Huang, W.-W., Lin, K.-L., Kuo, S.-C., and Chung, J.G. (2010). MJ-29 inhibits tubulin polymerization, induces mitotic arrest, and triggers apoptosis via cyclin-dependent kinase 1-mediated Bcl-2 phosphorylation in human leukemia U937 cells. J. Pharmacol. Exp. Ther. 334, 477-488. doi: 10.1124/jpet.109.165415

Yang, R., Zhang, S., Kong, D., Gao, X., Zhao, Y., and Wang, Z. (2012). Biodegradable polymer-curcumin conjugate micelles enhance the loading and delivery of lowpotency curcumin. Pharm. Res. 29, 3512-3525. doi: 10.1007/s11095-012-0848-8

Yazdani, D., Shahnazi, S., Rezazadeh, S. A., and Pirali, H. M. (2005). Review on yew tree (Taxus SPP.). J. Med. Plants 4, 1-8.

Zhou, M., Liu, Z., Zhao, Y., Ding, Y., Liu, H., Xi, Y., et al. (2010). MicroRNA-125b confers the resistance of breast cancer cells to paclitaxel through suppression of pro-apoptotic Bcl-2 antagonist killer 1 (Bak1) expression. J. Biol. Chem. 285, 21496-21507. doi: 10.1074/jbc.M109.083337

Conflict of Interest Statement: The authors declare that the research was conducted in the absence of any commercial or financial relationships that could be construed as a potential conflict of interest.

Copyright (c) 2015 Fridlender, Kapulnik and Koltai. This is an open-access article distributed under the terms of the Creative Commons Attribution License (CC BY). The use, distribution or reproduction in other forums is permitted, provided the original author(s) or licensor are credited and that the original publication in this journal is cited, in accordance with accepted academic practice. No use, distribution or reproduction is permitted which does not comply with these terms. 